\title{
An automated trainer for improving visual acuity in myopic adults
}

\author{
FRANK L. COLLINS, JR., RONALD L. BLOUNT, and KAREN M. GIL \\ West Virginia University, Morgantown, West Virginia 26506
}

\begin{abstract}
Several studies have found training procedures derived from the experimental analysis of behavior to result in improved visual acuity for myopic adults. The present paper describes an automated trainer that incorporates critical training components and eliminates excessive time demands of the fading and feedback procedures reported in the literature. Implications for standardization and long-term training are discussed.
\end{abstract}

Vision training is a somewhat controversial research area that has grown out of an environmental approach to the etiology of myopia (cf. Friedman, 1981). The relative importance of genetic vs. environmental factors has been debated throughout the literature; however, there is now growing acceptance of the contributions of environmental and behavioral influences (Birnbaum, 1981; Collins, Epstein, \& Gil, in press). One major problem with research in this area has been the inability to demonstrate substantial improvements in visual acuity (Collins et al., in press; Ricci \& Collins, 1981) because of a lack of standardized training programs and insufficient experimental control (Collins, 1981). The development of automated training devices and associated standardized training procedures may help remedy these problems.

Several studies have demonstrated that a vision training program using stimulus fading and verbal feedback results in improved acuity for myopic adults (Collins, Epstein, \& Hannay, 1979, 1981; Collins, Ricci, \& Burkett, 1981; Epstein, Collins, Hannay, \& Looney, 1978; Epstein, Greenwald, Hennon, \& Hiedorn, 1981). Basically, the fading and feedback training used in previous studies requires the use of an experimenter to randomly present stimulus letters at a distance at which the subject can identify the letters and then to gradually increase the presentation distance following successful identification of 10 consecutive presentations.

To date, all of the published reports have utilized trained research personnel. An automated trainer greatly reduces professional cost and increases the relative flexibility for training. In this paper, we describe a rela. tively inexpensive automated trainer for use in either laboratory or home settings. The trainer utilizes a Carousel slide projector interfaced with an Audio-Mate cassette tape recorder to advance visual stimulus slides

The authors are indebted to Leonard H. Epstein, whose support and sugpestions led to the development of this procedure. Reprint requests should be sent to Frank L. Collins, 311f Oglebay Hall, Department of Psychology, West Virginia University, Morgantown, West Virginia 26506. and to provide auditory feedback to the subject following each response. It is totally self-contained and can be used independently by the subject.

\section{DESCRIPTION OF THE TRAINER}

The major component of the trainer is an AudioMate 590 cassette tape player interfaced with a Kodak Carousel Custom $860 \mathrm{H}$ slide projector. Audio tapes are programmed so that they advance slides at a rate of one slide every $5 \mathrm{sec}$. Both the tape player and the slide projector are located on a movable stand so that the subject can view successive slides at various distances and receive auditory feedback regarding the correctness of his or her response.

\section{Stimulus Slides and Projector}

An 80-slide Carousel ( 2 by 2 in. slides) is used, although the number of slides is not critical. Alternate slides are blank, and slides containing mounted black letters centered on white paper are interspersed between the blank slides. The stimulus letters are dry transferable Prestype (Helvetica 1321.36 CLN), $10 \mathrm{~mm}$ high with details $2 \mathrm{~mm}$ in width, subtending visual angles of approximately $5 \mathrm{~min}$ and $1 \mathrm{~min}$ at a distance of $690 \mathrm{~cm}$ $(22.6 \mathrm{ft})$. These are identical to those used by Collins, Epstein, and Hannay (1979, 1981), Collins, Ricci, and Burkett (1981), and Epstein et al. (1978). The letters are randomly placed in the slide trays, and the 26 letters of the alphabet are included.

The projector, which is mounted on a wooden stand approximately $85 \mathrm{~cm}$ high, requires several modifications: First, the Ektanar C102-mm lens must be removed so that the slides can be seen by looking down the barrel of the projector. Second, the mirror mount assembly. which reflects light from the bulb to the slide, the heat absorbing glass, and the condenser lens must be removed. This reduces the brightness of the light from the projector.

Cassette Tape Player and Tapes

The Audio-Mate 590 cassette tape player is con- 
nected to the slide projector via the SYNC jack in the player. Tapes are programmed to pulse and advance the slide projector at a rate of one slide every $5 \mathrm{sec}$. During the 5-sec interval in which a blank slide is being presented, a $.5-\mathrm{sec}$ tone sounds $3 \mathrm{sec}$ into the interval. This serves as a signal to the subject to record his or her response and that feedback will follow. Immediately following the termination of the tone, a voice using the United States Naval Institute (1968) verbal equivalent for letters announces the letter that had previously been presented, providing feedback to the subject. We currently use 10 sets of different Carousel/cassette tape combinations.

\section{Subject's Seat}

A right-handed classroom-type desk with a writing surface is modified for use as the subject's seat. A chin rest is mounted to the desk by first at taching a $2 \times 4 \times 5$ in. wooden brace on the left under side of the writing surface. A $2 \times 2 \times 12$ in. wooden arm is attached to the brace with two bolts $2 \mathrm{in}$. apart. The bolts fit loosely through a 5-in.-long hole cut in the center of the wooden arm. This permits the height of the arm to be adjusted easily by tightening washers and wing nuts. A small, thin, wooden platform $(2 \times 3$ in.) is nailed to the top of the arm and covered by foam rubber and vinyl in order to form a comfortable, cleanable chin rest.

\section{Subject Limitations}

The severity of myopia directly affects the beginning training distance and rate of progress for each subject (Collins, Ricci, \& Burkett, 1981; Epstein et al., 1978). Subjects with myopia ranging from $20 / 25$ to slightly worse than 20/200 have been trained (cf. Epstein et al., 1978), and improvements were noted in most cases. However, the more severe the myopic condition, the slower is the rate of progress.

\section{BASIC TRAINING PROGRAM}

\section{Daily Dependent Measures}

Two measures are used each day to evaluate progress and determine the starting training distance. A pre- training acuity test (PAT; Collins, Ricci, \& Burkett, 1981 ) is used each day to determine the starting distance and to demonstrate maintenance from the previous session. Figure 1 illustrates the procedure. First, the subject arranges the apparatus so that the first two stimulus slides will be presented at $152.5 \mathrm{~cm}$. During the PAT, the volume of the tape player is turned down so that no feedback is provided and the subject starts the equipment, responds to the first two slides. and then stops the cassette system. Using provided keys, the subject checks the correctness or incorrectness of his or her response and presents two more slides at a farther distance if both previous slides were correctly identified or at a nearer distance if one or both slides were missed This is indicated on Figure 1 by plus and minus arrows. After the final distance is presented, the subject computes the farthest distance at which both letters were correctly identified and begins training at this distance.

After 100 training trials, a behavioral acuity measure is obtained. The behavioral acuity test (BAT; Epstein et al., 1978) involves the presentation of 10 stimulus letters at four distances $(152.5,305,457.5$, and $610 \mathrm{~cm}$, or $5,10,15$, and $20 \mathrm{ft}$, respectively). As with the PAT, the sound is lowered so that there is no feedback for each response.

\section{Training}

Each session consists of an adaptation/habituation period followed by the PAT, training, and the BAT. The adaptation/habituation period allows the subject to adjust to the absence of artificial refraction. At least $30 \mathrm{~min}$ before each training session, subjects are instructed to remove their glasses and to refrain from any near work activities such as reading and writing. Contact lenses must be removed at least $2 \mathrm{~h}$ before the training session. All subsequent training and testing sessions are conducted without lenses.

Each day the subjects consult a list indicating which tape/Carousel combinations are to be used for that session. The PAT is obtained and training begins. The volume is turned up on the tape player so that feedback is available following each letter. After 10 consecutive correct responses. the subject stops the tape and moves

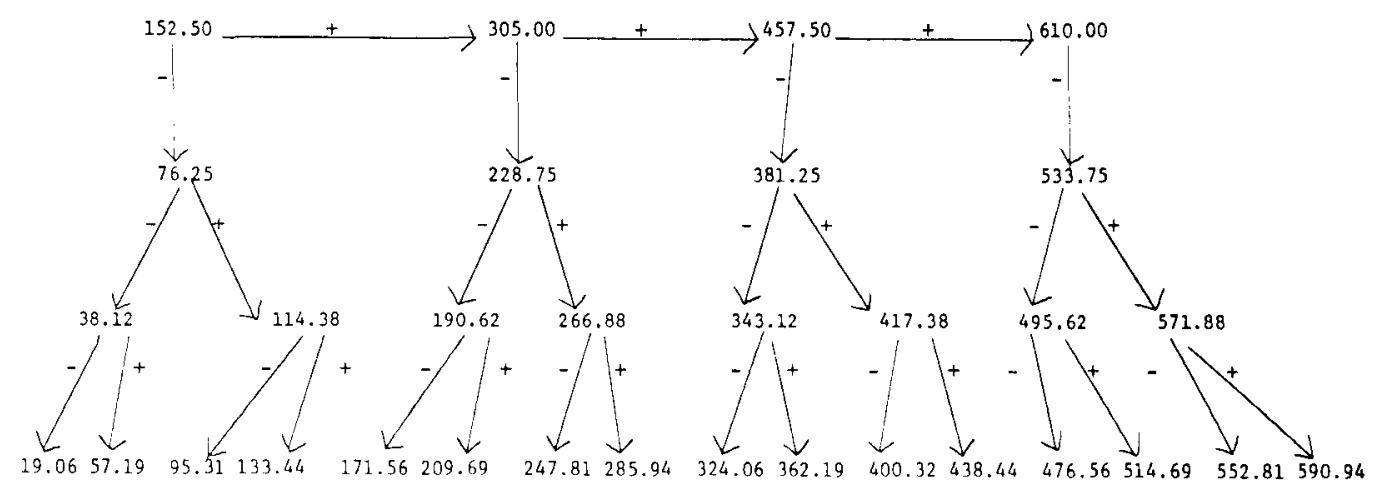

Figure 1 . Schematic outline of the pretraining acuity measure. 
the slide unit $20 \mathrm{~cm}$ farther away. If after 50 presentations, 10 consecutive correct responses are not obtained, the stimuli are moved $10 \mathrm{~cm}$ nearer. Any type counter can be used for monitoring consecutive correct and incorrect responses.

Throughout training, subjects are instructed to look, but not squint, at the stimuli and to concentrate on relaxing the visual system. It may be important to observe subjects during some of the early sessions to provide feedback, since many myopes are actually unaware of their squinting.

\section{DISCUSSION}

The present paper presents an automated fading and feedback procedure for improving visual acuity in myopic adults. The procedure by itself should not be construed as a "do-it-yourself" empirically evaluated myopia trainer. Rather, this paper is a detailed description of an automated training procedure that maintains those critical components of the fading and feedback training procedure, while allowing for a greater degree of standardization and more detail to the actual training program. Of course, additional research is needed in this new area (Collins et al., in press).

\section{REFERENCES}

Birnbaum, M. H. Concluding remarks. American Journal of Optometry and Physiological Optics, 1981, 58, 567-569.
Collıns, F. L. Behavioral medicine. In L. Michelson, M. Hersen, \& S. Turner (Eds.), Future perspectives in behavior therapy. New York: Plenum, 1981.

Collins, F. L., Epstein, L. H., \& GiL, K. M. Behavioral factors in the etiology and treatment of myopia. In M. Herson, R. M. Eisler, \& P. M. Miller (Eds.), Progress in behavior modification (Vol. 13). New York: Academic Press, in press.

Collins, F. L., Epste in, L. H., \& Hannay, H. J. Modification of myopia using fading and feedback: A case study. Behavior Therapist, 1979, 2(5), 28-29.

Collins, F. L., Epstein, L. H., \& Hannay, H. J. A component analysis of an operant training program for improving visual acuity in myopic students. Behavior Therapy, 1981, 12, 692-701.

Collins, F. L., Ricci, J. A., \& Burkett, P. A. Behavioral training for myopia: Long term maintenance of improved acuity. Behaviour Research and Therapy, 1981, 19, 265-268.

Epstein, L. H., Collins, F. L., Hannay, H. J., \& Looney, R. L. Fading and feedback in the modification of visual acuity. Journal of Behavioral Medicine, 1978, 1, 273-287.

Epstein, L, H., Greenwald, D. J., Hennon, D., \& Hiedorn, B. Monocular fading and feedback training: Effects on vision changes in the trained and untrained eye. Behavior Modification, 1981, 5, 171-186.

Friedman, E. Vision training program for myopia management. American Journal of Optometry and Physiological Optics, 1981, 58, 546-553.

Ricci, J. A., \& Collins, F. L. The role of psychology in the health care of ophthalmological disorders. Clinical Psychology Review, 1981, 1, 431-451.

United States Naval Institute. The bluejacket's manual (18th ed.). Annapolis, Md: Author, 1968.

(Received for publication October 23, 1981; revision accepted June 3, 1982.) 